\title{
DEPENDENCE OF THE SELECTED PROPERTIES OF THE MOTOR OIL ON THE CHARACTERISTICS ON POWER CONSUMPTION FOR ENGINES SUPPLIED WITH BIOGAS AND GAS
}

\author{
J. Kaszkowiak $^{*}$, M. Markiewicz-Patalon ${ }^{* *}$, P. Dorszewski ${ }^{* * *}$
}

\begin{abstract}
The results of the studies on the influence of the type of fuel - of natural gas and of biogas - and the manner of the motors' loading with spark ignition on the selected properties of the motor oil, are described in the study. In the first group the fuel was the biogas and in the second - the natural gas. The motors were subject to loads of constant and variable value. It was found, that the uniform loading of the combustion motor to a lesser degree causes degradation of the lubricating properties of a motor oil than in case of often loading's changes. A similar reaction was observed both for the motors supplied with biogas as well as with the natural gas.
\end{abstract}

Keywords: biogas, natural gas, motor oil, combustion engine

\section{Introduction}

Powering of combustion engines with biogas, becomes a more and more frequent manner of effective biogas use. Such a solution makes it possible to widen the possibilities of the biogas use not only for heat generation, but also for the electric energy's generation. Motors supplied with biogas, most often drive power generators, what allows for simple transfer of the generated power with the use of the common power network. Very often, the generated electric power is consumed directly in the place of its generation in different technological processes (for ex. sewage-treatment plants). Motors powered by biogas are most often the typical unit constructions with self-ignition following making of necessary modifications. Because of the variable biogas's supply, linking of motors powered with biogas with motors using natural gas is used quite often. The biggest hazard for durability of motors powered with biogas, is the presence of sulphur and silicon compounds in biogas.

The biogas's composition is differentiated, depending on the parent substance from which it is made of, thermal conditions and the presence of impurities (Kaszkowiak, 2014). At farm biogas plants, these are cultivated plants (corn, beets) and organic wastes used in the form of an additive or separately organic wastes that are most often used as a parent substance (Czekała et al., 2016). More and more often, in order to raise profitability, for production of biogas there are used overdue products of plant origin coming from the processes of storage and processing of fruits and vegetables (Zbytek et al., 2016). For this group there may also be included by-products formed during farm production, just like liquid manure or dung (Guangqing L. et al., 2009). It limits the costs of a raw material's obtaining in practice only for the costs of transport (Borowski et al., 2016) and it often allows for gaining an additional income on the wastes' utilization. Replacement of cultivated plants with wastes allows for the use of agrarian areas for food production (Bilcan, A., Le Corre, O. \& Delebarre, A., 2003). One should also mention the increasing share of sea algae as a parent substance for biogas plants (Mussgnug et al., 2010). As already mentioned,

\footnotetext{
Jerzy Kaszkowiak, PhD.: Faculty of Mechanical Engineering, UTP University of Science and Technology, Poland. Al. Prof. Kaliskiego 7, 85-796 Bydgoszcz, e-mail: kaszk@utp.edu.pl

** Marietta Markiewicz-Patalon, ing.: Faculty of Mechanical Engineering, UTP University of Science and Technology, Poland. Al. Prof. Kaliskiego 7, 85-796 Bydgoszcz, e-mail: markiewicz-patalon@wp.pl

*** Piotr Dorszewski PhD Faculty Faculty of Animal Breeding and Biology
} 
the composition of biogas may change. The scope of these deviations for biogas obtained in sewagetreatment plants is presented in Table 1.

Tab. 1: Composition of biogas generated in municipal waste-treatment plants (own study)

\begin{tabular}{cc}
\hline Gas & Waste-treatment plant \\
\hline Methane & $64-75 \%$ \\
\hline $\mathrm{CO}_{2}$ & $20-35 \%$ \\
\hline $\mathrm{CO}$ & $\leq 0.2 \%$ \\
\hline $\mathrm{H}_{2} \mathrm{~S}$ & $\leq 8000 \mathrm{ppm}$ \\
\hline $\mathrm{N}_{2}$ & $3-4 \%$ \\
\hline $\mathrm{O}_{2}$ & $0.5 \%$ \\
\hline
\end{tabular}

The costs of operation of motors powered with biogas, apart from the costs of fuel's obtaining depend to a big degree on outlays incurred on their functioning. There beleong the expenses on maintenance and repairs of drive units. Outlays for the replacement of the engine oil are one of the highest shares in the structure of expenses. On one hand, the replacement of oil after extended periods of operation favours lowering of the costs, however at the same time it may result in shortening of the motor's life and unfavourably influence the operating parameters (increase of fuel's consumption, increase of the noise level). In practice there are used either shortened period between oil exchange or relatively expensive periodical controls of its quality. Ensuring the correct quality of biogas, the period between subsequent replacements of the motor oil may depend on the manner of motors' loading. As presented by Chandra R. et al. (2011), the impact of the natural gas use as a fuel for supplying combustion motors results in general in similar results as in case of biogas, however due to smaller changes in composition, less unfavorable effects than in case of feeding with biogas are observed.

\section{Methods}

The studies were conducted in two groups (2 units in each) of motors with spark ignition, supercharged of identical construction. These motors were used to drive the electric power generators. The rated power of all the motors was identical and amounted to $380 \mathrm{~kW}$. Their load did not exceed $300 \mathrm{~kW}$ (about $75 \%$ of maximum power).

The first group of motors was powered with natural gas of the calorific value $32.8 \mathrm{MJ} \cdot \mathrm{m}^{-3}$. The gas is supplied by an external distributor. The declared composition of the natural gas is presented in the Table 2.

Tab. 2: Composition of the natural gas at the time of the studies' conducting (data of the distributor)

\begin{tabular}{cc}
\hline Composition of natural gas & Mean content \\
\hline Methane & $97.8 \%$ \\
\hline Nitrogen & $1.0 \%$ \\
\hline Propane, butane, ethane & $1.0 \%$ \\
\hline Other & $0.2 \%$ \\
\hline
\end{tabular}

The second group of motors was powered with biogas generated from wastes from the municipal sewagetreatment plant. The calorific value of biogas was subject to slight changes at the time of the conducted studies and amounted to from $17.7-18.1 \mathrm{MJ} \cdot \mathrm{m}^{-3}$. The biogas's parameters were monitored systematically with the use of the biogas analyzer BIOTEX MultiPoint. The composition of biogas is presented in the Table 3. Changes in the biogas's composition following treatment, did not exceed $1 \%$ of the value.

In order to reach the identical power of motors' operation at different energetic parameters of biogas and natural gas, a professional reprogramming of steering units (of computers) with motors. The motors of both the groups were located in a common, unheated room, with free air flow, combustion gases were led outside. Fluctuations of the internal rooms' temperatures in the whole period of the studies did not exceed 
$15{ }^{0} \mathrm{C}$. All the motors were in a very good technical state, (not more than 2 years from the major repair). Prior to commencement of each measurement period, the air filter, the engine oil and the engine oil's filter were replaced.

Tab. 3: The mean contents of the selected compounds in biogas in the period of the conducted studies

\begin{tabular}{ccc}
\hline Biogas content & Mean value prior to treatment & Mean value following treatment \\
\hline Metane & $65.25 \%$ & $65.25 \%$ \\
\hline Hydrogen sulphide & $59 \mathrm{ppm}$ & $11 \mathrm{ppm}$ \\
\hline Carbon dioxide & $35 \%$ & $35 \%$ \\
\hline Ammonia & $0 \mathrm{ppm}$ & $0 \mathrm{ppm}$ \\
\hline
\end{tabular}

The measurement cycle for each motor amounted to 800 hours, the selected oil's parameters were controlled every 200 hours of the engine's operation. There were tested: the oil's internal friction, the acid value, the basic value, the content of silicon, sodium, chlorides, iron and copper. In each measurement group one of the motors operated at a constant load, and the second one with the changing load as to the value. For motors operating at the constant load, the load variability did not exceed $1 \%$. The volume of the generated electric power during one measurement cycle was assumed to be the load indicator. For motors loaded in a constant manner, the generated energy amounted to $240000 \mathrm{kWh}$ (864 GJ). In case of motors operating with a variable load, the changes of the used power changed within the limits $115 \mathrm{~kW}$ $310 \mathrm{~kW}$. The generated power amounted on average to $117600 \mathrm{kWh}$ (423.36 GJ), so it was for 51\% lower than for motors operating with the constant load. Each measurement cycle was repeated three times. The tested oil parameters were subject to the statistical analysis with the use of the Tukey test at the significance level 0.05 .

In the tested conditions, no statistically significant differences in the oil's internal friction were found, irrespective of the type of load or the used fuel. Occurrence of statistically significant differences in the value of the acid number and the basic number, content of silica, sodium and chlorides also was not found. Statistically significant there were the differences in the content of iron and copper in oil. Their content is presented in charts 1 and 2 .

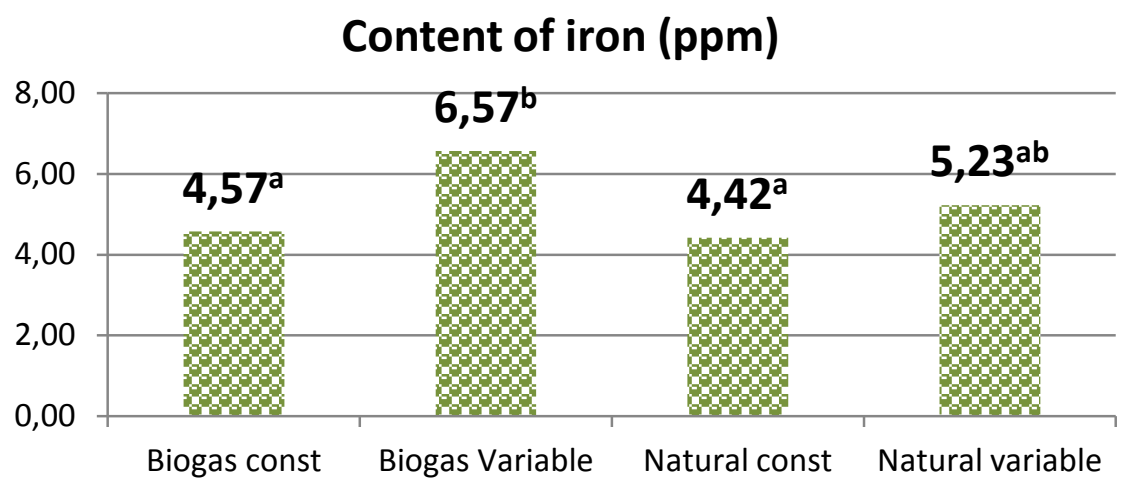

Fig. 1: The mean content of iron in oil for motors powered with biogas and natural as at constant and changing load

In the whole scope of the studies, the internal friction, the content of silica and iron in oil did not exceed the allowed values. Only the acid number reached the values considered to be the boundary ones (Piec, 2012). In the whole scope of the studies, the internal friction, the content of silica and iron in oil did not exceed the allowed values. Only the acid number reached the values considered to be the boundary ones (Piec, 2012). 


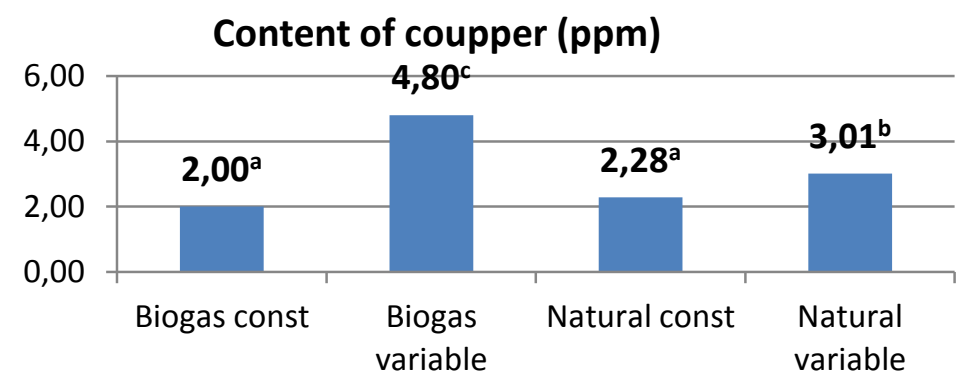

Fig. 2: The mean content of copper in oil for motors powered with biogas and natural gas at constant and changing load

\section{Conclusions}

There were found no statistically significant differences in viscosity of oil irrespective on the type of loading or the used fuel, in the values of the acid and basic value, the content of silicon, sodium and chlorides. Occurrence of statistically significant differences in the content of copper and iron in oil were found. Statistically significant differences in the content of iron in the oil were found between the motors supplied with biogas at the variable motor's loading and the motors supplied with biogas at constant loading. A similar regularity was observed for motors supplied with the natural gas. The content of iron in the motor oil proved to be higher than in case of irregular loading of motors for both the tested fuels - the natural gas and for biogas. For the motors supplied with biogas of variable loading, the increase of the iron's content amounted to more than $40 \%$ as compared to motors with the constant loading. For the motors supplied with the natural gas, the increase of the iron content had a lower value and amounted to more than $18 \%$. For the content of copper in the motor oil, there was found the occurrence of statistically significant differences for the motors supplied with biogas at the constant and variable loading, for the motors supplied with the natural gas at the constant and the variable loading, and between the content of the copper for the motors loaded in a variable manner and supplied with the biogas and the natural gas. In case of the motors supplied with the biogas loaded in a variable manner, the content of copper in oil was almost for $150 \%$ higher than for the motors loaded in a constant manner. A similar direction of changes in the content of copper in the motor oil was found for motors supplied with the natural gas, however that increase was smaller and amounted to approx. 18\%. The differences in the content of copper for the motors supplied with biogas and the natural gas at their constant loading proved insignificant. The obtained results are subject to further analyses in order to establish the occurrence of differences at the subsequent times of the motors' operation.

\section{References}

Bilcan, A., Le Corre, O. Delebarre, A. (2003) Thermal efficiency and environmental performances of a biogas-diesel stationary engine Environmental Technology Vol. 24 , No. 9 p.1165-73

Borowski, S., Knopik, L., Markiewicz-Patalon, M., Brzostek, A. (2016) Assessment of transport substrates for selected agricultural biogas plantW: Proceeding of 6th International Conference on Trends in Agricultural Engineering Prague, 07-09.09.2016 p.76-80,

Chandra, R., Vijay, V.K., Subbarao P.M.V., Khura, T.K. (2011) Performance evaluation of a constant speed IC engine on CNG, methane enriched biogas and biogas. Applied Energy Volume 88, Issue 11, p. 3969-3977

Czekała, W., Bartnikowska, S., Lewicka, A., Bugała, A., Zbytek, Z., Lewicki, A., (2016) Economic and energy efficiency of the solid biofuels produced from digested pulp $3^{R D}$ International Conference on Chemical and Biological Sciences Amsterdam p. 4001-5

Guangqing, L., ,Ruihong, Z., ', Hamed, M. El-Mashad, Renjie D. (2009) Effect of feed to inoculum ratios on biogas yields of food and green wastes Bioresource Technology Vol. 100, No 21 p. 5103-5108

Mussgnug, J.H., Klassen, V., Schlüter, A., Kruse, O. (2010) Microalgae as substrates for fermentative biogas production in a combined biorefinery concept Journal of Biotechnology Vol. 150, / 1, p. 51-56

Kaszkowiak, J. (2014) Technologique of application of additives facilitating silage of plant materials used for production of biogas, Journal of Research and Applications in Agricultural Engineering - 2014, 59, 1, 52-54, pISSN: 1642-686X

Zbytek, Z., Dach, J., Pawłowski, T., Smurzynska, A., Czekała, W., Janczak , D. (2016) Energy and economics potential of maize straw used for biofuels production $3^{R D}$ International Conference on Chemical and Biological Sciences Amsterdam p. 040081-5 